\title{
CONHECIMENTOS INTERDISCIPLINARES DO EXÉRCITO BRASILEIRO: UM MAPA PARA A SOCIEDADE CIVIL
}

\section{CONOCIMIENTO INTERDISCIPLINARIO DEL EJÉRCITO BRASILEÑO: UN MAPA PARA LA SOCIEDAD CIVIL}

Márcio da Silva Finamor a

\begin{abstract}
RESUMO
Introdução: neste ensaio pretendemos fazer uma discussão teórica e descritiva sobre as dimensões dos conhecimentos produzidos no Exército Brasileiro (EB). Objetivo: 0 objetivo é apresentar para a sociedade brasileira em geral, especialmente a civil, esse horizonte inexplorado por eles. Mostrar que o EB é muito mais que o universo do quartel e das organizações militares, estabelecendo uma relação entre o conhecimento (ciências militares) e sua diversidade de disciplinas introduzidas nas Escolas Militares do Brasil para os compatriotas. Metodologia: o ensaio constitui-se em uma abordagem teórica e qualitativa - pela amostragem por conveniência -, selecionando militares e civis especialistas no tema ciência militares, ensino acadêmico e prática profissional: convidados a responder um questionário e discutir acerca dos conhecimentos interdisciplinares do EB sobre o prisma da sociedade civil. Resultados: aponta perspectivas promissoras do engajamento e compartilhamento dos conhecimentos para a sociedade civil; mostra as fontes de informação e caminhos estratégicos de acesso e busca de significativos conhecimentos até agora desconhecidos (pelos civis), com isso, estabelece maiores esforços por parte do EB para a manutenção e conservação desta administração: troca de informações, conhecimentos e, respectivamente, meios para inovar e criar vantagens nestes dois cenários: civil e militar. Conclusões: por fim, considera-se que a interdisciplinaridade dentro do EB é uma demanda essencial e emergente para os dias atuais, ela dar-se-á e facilitará maior engajamento para interagir e socializar no ambiente civil, assim como maior visibilidade na sociedade civil e acadêmica, seja no Brasil ou no exterior, como fator-chave no desenvolvimento organizacional militar e na dimensão humana.
\end{abstract}

Descritores: Interdisciplinaridade. Conhecimento militar. Produção intelectual do Exército Brasileiro.

\section{1 À GUISA DA INTRODUÇÃO}

Este ensaio pretende traçar um breve panorama teórico e explicativo

\footnotetext{
a Mestre em Ciência da Informação pelo convênio entre o Instituto Brasileiro de Informação em Ciência e Tecnologia (IBICT) e a Escola de Comunicação (ECO) da Universidade Federal do Rio de Janeiro (UFRJ). Email: marciofinamor@gmail.com
} 
sobre os conhecimentos interdisciplinares (integração de disciplinas) na produção acadêmica, na prática profissional e intelectual dos militares da força Exército Brasileiro (EB), isto é, apresentar os significativos conhecimentos desta força para a sociedade civil em geral (civil, acadêmica, empresarial) e a importância deste conhecimento em ser compartilhado e exposto para a sociedade. Assim, este ensaio procura desmistificar de uma vez estereótipos sobre os militares quanto ao fazer da sua profissão para além da proteção do país.

O EB é uma das três Forças Armadas do Brasil. É responsável, no plano externo e interno, pela defesa do nosso País. Visa garantir a ordem e a lei aos cidadãos que nele vivem. Para isso, é necessário, através dos cursos, da formação específica e de disciplinas inovadoras, um alto conhecimento prático e acadêmico para garantir a defesa. Esse conhecimento engloba diversas especialidades e equipes integradoras, trabalhando em conjunto.

Dentre essas especialidades, o nosso tema, neste ensaio, será a participação e coordenação do EB em campanhas e Organizações Militares (OM) - sociais e de pesquisas científicas Lato sensu e Stricto sensu em ciências militares - sendo as principais Armas, Quadros e Serviços: Infantaria (INF); Cavalaria (CAV); Artilharia (ART); Engenharia (ENG); Comunicações (COM); Intendência (INT); Material Bélico (MB) e curso de saúde (quadro de médicos), bem como as qualificações militares (QMs), Quadro Complementar de Oficiais (QCO) e específicas às atividades da Força.

Cada uma dessas especialidades e qualificações possui suma importância para o EB e para a Sociedade/Nação. A Força está continuamente preparando-se para atuar em situações de conflito ou guerra, ainda que vivamos em tempos de paz é preciso estar preparado. Neste cenário, os militares devem estar prontos - em termos militares - para qualquer circunstância. Por consequência, existem esforços por parte de cada força, entre eles o: físico, emocional, psicológico, operacional, mental, intelectual, tecnológico, estratégico, logístico, administração, gestão e outros. Para dar conta desta conjuntura o EB possui diversas Escolas Militares, acadêmicas/científicas para formarem profissionais militares aptos em qualquer uma das armas, quadros, serviços e 
especialidades na gestão operacional, organizacional, estratégica e social.

Assim sendo, sobre as características desse profissional, destacam-se abaixo as principais Escolas e Institutos do EB que venham a doutrinar - formar o militar - em continuidade à sua preparação e instrução para as suas qualificações:

- Escola de Formação Complementar de Oficiais (EsFCEx);

- Academia Militar das Agulhas Negras (AMAN);

- Instituto Militar de Engenharia (IME);

- Escola de Sargentos das Armas (ESA);

- Escola Preparatória de Cadetes do Exército (EsPCEx);

- Escola de Sargentos de Logística (EsSLog);

- Escola de Aperfeiçoamento de Oficiais (EsAO);

- Escola de Comando e Estado-Maior do Exército (ECEME);

- Escola de Educação Física do Exército (EsEFEx);

- Escola de Sargentos de Logística do Exército Brasileiro (EsSLog);

- Escola Preparatória de Cadetes (EsPCEx);

- Escola de Sargentos das Armas (EsSA) e,

- Escola de Saúde do Exército (EsSEx).

Com a evolução tecnológica, das formas e métodos de ensino, as escolas militares e sua divisão de ensino vêm aprimorando essas técnicas e, consequentemente, trazendo maiores desafios e melhorias para a Força e seus respectivos militares. Levando esses profissionais a ajustarem-se às capacidades técnicas, de gestão, operacional e estratégias, sejam operacionalizantes ou de conhecimento científico propriamente dito. De modo que os atributos como: criatividade, capacidade de adaptação, produção e criação de novos conhecimentos - intelectual ou prático - sejam aprimorados.

Dessa forma, possibilitando ao profissional militar do EB um conjunto de conhecimentos, culturas e diversas disciplinas, tornando-o capacitado para acompanhar a evolução da sociedade militar e principalmente da civil, com o apoio das ciências e do ofício do militar ao longo da sua carreira.

O Departamento de Educação e Cultura do Exército (DECEx) e os departamentos de ensino em ciências militares do EB estabelecem em seus 
novos preceitos a Modernização do Ensino Militar. A inovação no ensino não se estabelece somente na tecnologia, mas principalmente nos valores aprendidos. As disciplinas e ensinos diversificados fazem parte desta nova modernização ao que academicamente intitula-se como conhecimentos interdisciplinares compartilhados, produzidos e aperfeiçoados no EB, configurando o ensino para as mudanças pragmáticas no cenário mundial, brasileiro e social. Com isso, torna-se necessário refletir sobre essa nova postura educacional militar que, certamente, contribuirá para a formação do profissional militar no futuro e principalmente para a dimensão humana de nossos cidadãos.

Existem variados estudos sobre a importância e perspectivas desse ensino para os militares. Como a Ciência da Computação sobre os estudos de inteligência artificial para as tecnologias de defesa e guerra. Do campo da ciência da Administração para organização, planejamento e ação no âmbito militar como teorias e práticas. Por isso, o foco principal neste ensaio é justamente dar maior visibilidade a esse novo ensino e à sua importância para a sociedade civil brasileira, a saber: da relevância do estudo, da divulgação e do compartilhamento destes conhecimentos interdisciplinares no Exército Brasileiro para as pessoas desconhecedoras de tal saber.

É sobre esse olhar que pretende-se discutir ao longo desse ensaio. A importância da divulgação do conhecimento adquirido e produzido no EB pelos militares, que ele seja evidenciado e compartilhado, ou seja, mostrar como pode ser feito o acesso, busca e compartilhamento deste conhecimento, a fim de mostrar que os militares são mais que um ser humano aguerrido. Portanto, procura-se trazer à tona discussões acerca dos conhecimentos interdisciplinares do EB, as relevantes Escolas militares, e o que esses conhecimentos militares podem oferecer para a sociedade civil, em busca de uma filosofia humanista e emergente em tempos conflituosos. A saber: qual a importância e relevância da produção intelectual da área das ciências militares do EB para a sociedade civil em geral?

\section{NATUREZA INTERDISCIPLINAR DO EXÉRCITO BRASILEIRO}

O ensino, cultura, doutrina, práticas de ensino e regras em geral do EB 
surgiram através de trocas entre especialistas do mundo todo e pelas relações das forças mundiais quanto a suas doutrinas e aprendizagem em consonância com benefícios e oportunidades de avançar da Força. Outras práticas foram instituídas nas Escolas superiores ao saber dos embates entre diferentes modelos de organização funcional e de hierarquização de saberes e métodos. Como também das diversas "missões" estrangeiras, assim como das visitas de professores brasileiros à Europa e à América, bem como de generais e intelectuais de diversas forças internacionais de outras modalidades de relações internacionais, resultaram diferentes formas de apropriação de modelos, de assimilação de critérios, atividades de rotina e formas de avaliação, que acabaram por definir e redefinir o próprio perfil das instituições, que, também no plano das ideias e dos projetos, manifestarão ascendência de determinados modelos de formação profissional militar e intelectuais. As relações com os modelos estrangeiros será mais que a reprodução destes ensinos, pois, revelará os esforços de produzir uma ciência militar brasileira, moderna, com a qual as instituições irradiadoras e seus intelectuais pudessem travar diálogos francos com os padrões internacionais de excelência, aceitos e compartilhados por uma comunidade científica supranacional (WARDE, 2001 apud GRUNENNVALDT, 2005).

Neste ensaio:

[...] tentaremos apresentar as principais motivações desse empreendimento, bem como as justificações que poderão ser invocadas em seu favor. Tudo isso, no contexto de uma epistemologia das ciências humanas, às voltas com suas "crises" e com seus impasses metodológicos. A resolução dessas crises coincide pelo menos em parte, com os objetivos a que se propõe o método interdisciplinar. (JAPIASSU, 1976, p. 53, grifo nosso).

Em todas as áreas dos saberes, as Instituições e Organizações não foram criadas do nada. Relativamente foi arquitetado a partir de trocas de informações e conhecimentos compartilhados, de integração entre esses conhecimentos e interação entre os indivíduos, isto é, criado em apoio a algo, seja pragmático ou abstrato. De modo geral, construído a partir de observações, métodos apreendidos, olhar crítico e holístico diante de situações e problemas em geral. Diante do novo, do subjetivo e intersubjetivo. Da mesma forma o EB. Essa Força 
foi criada a partir de situações adversas, desde em tempos remotos até os dias atuais, foi empregada a partir de episódios decisivos em batalhas históricas, como as Batalhas dos Guararapes e Insurreição Pernambucana, dentre outras. Sobre esse cenário, aqui não pretende-se aprofundar no desenvolvimento histórico e eventos reais do EB, e sim mostrar que a interdisciplinaridade está nas origens desta "ciência militar" que pode ser criado, gerenciado e modificado. Dentre todas as áreas do conhecimento, instituições e organizações se apoiam em outras áreas do conhecimento, em métodos, em estudos de casos, em teorias aplicadas e testadas que deram certo ou não para reformularem suas teses. Em tecnologias, instrumentos e aplicações, de disciplinas, ciências e doutrinas de diversas áreas constituem a evolução e inovação de qualquer empreendimento. $\mathrm{O}$ conjunto desses mecanismos está ancorado no método interdisciplinar, uma propriedade inata a qualquer força, instituição, organização e áreas em geral do conhecimento.

Posto isso, destaca-se que a interdisciplinaridade possui uma das características pela intensidade das trocas entre os especialistas e pela integração das disciplinas. Seja num mesmo projeto de pesquisa, em ambientes de salas de aulas e de cursos, de trocas de informações e recursos entre as armas do EB (conhecimento prático, intangível e estratégico). Em termos de interdisciplinaridade ter-se-ia uma reciprocidade, ou, melhor dizendo, um regime de copropriedade, de interação, que irá possibilitar o diálogo entre os interessados. Isso poder-se-ia de modo presencial e virtual. A interdisciplinaridade depende, então, basicamente, de uma mudança de atitude perante o problema do conhecimento, da substituição de uma concepção fragmentária pela unitária do ser humano e de práticas construtivas, conforme aponta Fazenda (1993).

O sistema de ensino no $\mathrm{EB}$, andamento dos processos e desenvolvimento organizacional operam de uma forma interdependente do Governo Federal, Estado, Forças Armadas, sociedade, educação e ensino militar. Perpassando por reformas, processos e inovações que influenciam a confeç̧ão das normas, dos novos ensinos e dos interesses das forças sobre o quesito pedagógico, científico e valorativo do EB. Dessa forma, criaram-se elementos essenciais para 
a ampliação e inovação na formação do profissional militar, amparados nas novas modalidades pedagógicas evidenciadas na área deste conhecimento.

Para Magalhães (2010), o ethos ${ }^{1}$ militar do ensino ocorreu em favor de uma racionalidade pedagógica centrada em valores e categorias de análise completamente opostos: ao invés da subordinação absoluta do indivíduo ao grupo e à Instituição (holismo), a ponderação das necessidades emocionais e cognitivas dos educandos; ao invés do primado irrestrito da hierarquia, a menção a critérios racionais-legais de exercício de liderança; no lugar da onipresença do ascetismo radical, a defesa da utilização eventual do princípio da aprendizagem prazerosa, de uma concepção construtivista da aprendizagem integral e totalizante.

"A Força deverá manter-se em permanente processo de transformação, buscando, desde logo, evoluir da era industrial para a era do conhecimento" (BRASIL, 2012, p. 76). Neste quesito, o que se pretende, portanto, como instigação da força, não é propor a superação de um ensino organizado por disciplinas, mas a criação de condições de ensinar em função das relações dinâmicas entre as diferentes disciplinas, tecnologias, métodos e meios, aliandose aos problemas da sociedade. Assim, a interdisciplinaridade torna-se possível, então, na medida em que se respeite a verdade e a relatividade de cada disciplina, tendo-se em vista um conhecer melhor e inovar diante de cada especialidade (FAZENDA, 2011).

Sobre esses desafios da interdisciplinaridade e de um olhar do porvir, é preciso esforços afetivos e efetivos para os sujeitos, em que visem à construção de vínculos sobre ações que resultem um bem-estar entre os envolvidos. Dessa forma:

O homem está no mundo, e pelo próprio fato de estar no mundo, ser agente e sujeito do próprio mundo, e deste mundo ser Múltiplo e não Uno, torna-se necessário que o homem se conheça em suas múltiplas e variadas formas, para que possa compreendê-lo e modificá-lo. Nesse sentido, o homem que se deixa encerrar numa única abordagem do conhecimento vai adquirindo uma visão deturpada da realidade. Ao viver, encontra

\footnotetext{
1 "Ethos é o conjunto de traços e modos de comportamento que conformam o caráter ou a identidade de uma coletividade. Em Sociologia, é uma espécie de síntese dos costumes de um povo". Fonte: Wikipédia (Ethos) https://pt.wikipedia.org/wiki/Ethos
} 
uma realidade multifacetada, produto desse mundo, e evidentemente mais oportunidades terá em modificá-la na medida em que a conhecer como um todo, em seus inúmeros aspectos [...] A interdisciplinaridade visa à recuperação da unidade humano através da passagem de uma subjetividade para a intersubjetividade e, assim sendo, recupera a ideia primeira de Cultura (formação do homem total), o papel da escola (formação do homem inserido em sua realidade) e o papel do homem (agente das mudanças no mundo) (FAZENDA, 2011, p. 81-82, grifo nosso).

A interdisciplinaridade não dilui as disciplinas, ao contrário, mantém sua individualidade e integração com outras. Porém, integra as disciplinas a partir da compreensão das múltiplas causas ou fatores que intervêm sobre a realidade e trabalha todas as linguagens necessárias para a constituição de novos conhecimentos, comunicação e negociação de significados e registro sistemático dos resultados (BRASIL, 1999). Nesse sentido, a interdisciplinaridade torna-se uma prática indispensável, já que ela pressupõe uma prática dialógica no enfrentamento da interdisciplinaridade da dupla barreira: integração entre conhecimentos e interação entre pessoas (FAZENDA, 2008).

Neste quesito, Japiassu (1976) destaca que:

[...] do ponto de vista integrador, a interdisciplinaridade requer equilíbrio entre amplitude, profundidade e síntese. A amplitude assegura uma larga base de conhecimento e informação. A profundidade assegura o requisito disciplinar e/ou conhecimento e informação interdisciplinar para a tarefa a ser executada. A síntese assegura o processo integrador. (JAPIASSU, 1976, p. 65-66).

Para esse autor, o empreendimento da interdisciplinaridade, seja em qualquer organização, ou instituição, neste caso organização militar - força todas as vezes em que ele conseguir incorporar os resultados de várias especialidades, que tomar de empréstimo a outras disciplinas determinados instrumentos e técnicas metodológicas, fazendo uso dos esquemas conceituais e das análises que se encontram nos diversos ramos do saber, a fim de fazê-los integrarem e convergirem, depois de terem sido comparados e julgados coletivamente. Assim, pode-se dizer que o papel específico da atividade interdisciplinar consiste, primordialmente, em lançar uma ponte para ligar as fronteiras que haviam sido estabelecidas anteriormente entre as disciplinas com 
o objetivo preciso de assegurar a cada uma seu caráter propriamente positivo, segundo modos particulares e com resultados específicos de cada disciplina, curso e intenção pedagógica (JAPIASSU, 1976).

A interdisciplinaridade no EB é um processo de aprender e ensinar entre as armas. Diante das dificuldades, dos cenários possíveis e das relações subjetivas e intersubjetivas ${ }^{2}$ dos militares - aos quais verificar-se nas próximas seções - caminhos que engendram através das demandas da sociedade, do social e principalmente das ferramentas e instrumentos tecnológicos. A presença de diferentes métodos e de tecnologias relacionadas ao seu processo, de coleta de dados, informação e conhecimento constituiu o enfoque interdisciplinar no contexto mais amplo nos setores da nação.

Onde o mundo globalizado, as atividades e competências assumem um novo posicionamento, pois foram remodeladas por técnicas intensas de inovação. Com as Tecnologias de Informação e Comunicação - TIC como auxiliadoras da disseminação de informações, apoio ao compartilhamento do conhecimento e sua segurança, acesso e preservação, bem como da geração de conhecimento. Assim, a Força deve acompanhar as mudanças e, como também, a evolução da técnica e do uso difundido da tecnologia a serviço da informação e do conhecimento, transpondo barreiras físicas e institucionais e possibilitando a esses profissionais que mostrem o seu potencial e tornem pública sua gama de atuações, conhecimentos e inovações que muitas das vezes é desconhecida.

\footnotetext{
2 "[...] a intersubjetividade é necessariamente o campo no qual, sobre fundo de integração social, a razão "discursiva" e "comunicacional" apresenta, visando a outros e numa busca de consensualidade, uma conduta "processual" de argumentação e de justificação". Já para Japiassú e Marcondes (2006), a intersubjetividade é a interação entre diferentes sujeitos, que constitui o sentido cultural da experiência humana. $O$ problema da intersubjetividade está relacionado à possibilidade de comunicação, ou seja, de que o sentido da experiência de um indivíduo, como sujeito, seja compartilhado por outros indivíduos. Trata-se de noção encontrada contemporaneamente na fenomenologia e na filosofia analítica da linguagem com o objetivo de superar o subjetivismo e o solipsismo. A objetividade de vários sujeitos concordando quanto ao sentido de algo ou quanto a um resultado determinado (JAPIASSÚ; MARCONDES, 2006, p. 106).
} 


\section{A INTERDISCIPLINARIDADE A PARTIR DAS NOVAS CONFIGURAÇÕES TECNÓLOGICAS E DA SOCIEDADE DO CONHECIMENTO E DA INFORMAÇÃO}

Distanciar das tecnologias é regredir nos processos educacionais e interdisciplinares. A tecnologia é essencial para promover pesquisas, acesso às informações e conhecimentos de fácil alcance, viabilizando, assim, processos de aprendizagem de uma forma acessível e simples. Uma vez que, as mudanças na contemporaneidade em relação às tecnologias, ao acesso às informações, conhecimentos, e às conjecturas das relações interpessoais é possível verificar que a globalização modificou as redes de relacionamentos e o seu desenvolvimento entre os indivíduos, serviços e relações. Provocou mudanças no que configura uma sociedade, que vive uma reinvenção de valores, de interação e discussão na convivência social e no fazer do labor humano, seja através dos modos presenciais como através das sofisticações das tecnologias a distância.

Deste modo, a habilidade ou inabilidade de uma sociedade em dominar as tecnologias ou incorporar-se às transformações das sociedades, fazer uso e decidir seu potencial tecnológico, remodela a sociedade em ritmo acelerado e traça a história e o destino social dessas sociedades; remetendo que essas modificações não ocorrem de forma igual e total em todos os lugares, ao mesmo tempo e instantânea a toda realidade, mas sim é um processo temporal, e, para alguns, demorado, conforme aponta Castells (1999).

As TIC desempenham um papel de infraestrutura na Era da Informação e do Conhecimento, que envolve também aspectos humanos, gerenciais e estratégias, seja no seu uso ou de auxílio à aprendizagem. As tecnologias influenciam no desenvolvimento profissional, acadêmico e outros, auxiliam no compartilhamento da informação e conhecimento, na coleta de informações, busca e acesso, bem como na coleta de dados quantitativa e qualitativamente, imprimindo-lhe novas características. A tecnologia é um poderoso instrumento na formação das pessoas, servindo de suporte à Gestão da Informação e do Conhecimento nas empresas. No entanto, o diferencial do uso das tecnologias 
é o seu saber útil de forma estratégica, isto é, o ser humano é bombardeado de informações a todo momento com o apoio das tecnologias, mas é necessário possuir capacidades e competências suficientes para aproveitá-las de forma efetiva e competitiva (saudável).

Beal (2011), na área tecnológica, destaca que a informação é um elemento essencial para a criação, implementação e avaliação de qualquer estratégia. Sem o acesso às informações adequadas a respeito das variáveis internas e do ambiente onde a organização se insere, os responsáveis pela elaboração da estratégia não têm como identificar os pontos fortes e fracos, as ameaças e oportunidades, os valores corporativos e toda a variedade de fatores que devem ser considerados na identificação de alternativas e na tomada de decisões.

Já previa Pierre Lévy que as tecnologias e o seu uso se tornariam o ciberespaço, interconexão dos computadores do planeta, que se tornou a principal infraestrutura de produção, transação e gerenciamento econômicos. Será em breve o principal equipamento coletivo internacional da memória, pensamento e comunicação. Em resumo, em algumas dezenas de anos, o ciberespaço, e também suas comunidades virtuais, suas reservas de imagens, suas simulações interativas, sua irresistível proliferação de textos e de signos, será o mediador essencial da inteligência coletiva da humanidade (LÉVY, 1999).

Nesse sentido, é importante destacar os processos alinhados a esses desenvolvimentos organizacionais em que estão a gestão da informação ${ }^{3}$ e do conhecimento, que são estratégias corporativas, tecnológicas e humanas que visam um efetivo uso da informação para a geração de conhecimentos e de estratégias nas organizações, assim como o resultado da fusão desses processos possibilitando a geração de outro processo mais elaborado e bemestruturado: estratégias com sabedoria.

\footnotetext{
${ }^{3}$ Um dos processos e meios que facilitam o uso da informação é a Gestão da Informação (GI). Esse processo envolve a seleção e o processamento da informação, de modo a responder a uma pergunta ou a necessidade de resolver um problema, tomar uma decisão, negociar uma posição ou entender uma situação. Logo, no contexto organizacional, usar a informação está relacionado aos processos de tomada de decisão na organização, como também ao uso estratégico, a agregar novas ideias, à comunicação e à socialização (CAVALCANTE; VALENTIM, 2010, p. 249).
} 
O objetivo das ferramentas de gestão do conhecimento é modelar parte do conhecimento que existe nas cabeças das pessoas e nos documentos corporativos, disponibilizando-o para toda a organização. A mera existência de conhecimento na empresa é de pouco valor, se este não estiver acessível. Com estas ferramentas pretende-se que o conhecimento possa fluir através de redes de comunidades, transformando a tecnologia em um meio e o conhecimento em uma mensagem (DAVENPORT; PRUSAK, 1998).

Afirma Senge (1998) que as organizações que tencionam em criar visões compartilhadas estimulam continuamente seus integrantes a desenvolverem suas visões pessoais; se não tiverem sua própria visão, restará às pessoas simplesmente "assinar embaixo" da visão do outro. O resultado é a aceitação, e nunca o comprometimento. Por outro lado, pessoas que têm uma forte noção de direção pessoal podem se juntar para criar uma sinergia poderosa, inovando e gerenciando estratégias em busca do que realmente desejamos no ambiente organizacional e pessoal. As "organizações que aprendem" não se esgotam apenas na identificação dos vários tipos de conhecimento ali existentes. Importante é, também, buscar mecanismos de integração dos conhecimentos tácito, explícito e cultural.

A sociedade da informação e do conhecimento necessita da interdisciplinaridade para o seu funcionamento e gerenciamento. Cada processo, serviço informacional e estratégias a serem elaboradas dependem de certo fator metodológico, de certa disciplina apreendida e já testada, certo saber científico ou de outra área em consonância com outro saber, e, dessa forma, juntam-se esses saberes para melhor atender a comunidade, a organização ou a equipe.

Por fim, Senge (1990) mostra que as organizações de aprendizagem fundamentam-se no que ele chama de cinco "disciplinas", que são:

O domínio pessoal: aprender a expandir as capacidades pessoais; criar um ambiente empresarial que estimule todos os participantes alcançando, assim, as metas escolhidas; estimular os trabalhadores a buscarem e alcançarem seus objetivos sem medo de errar.

Modelos mentais: consiste em refletir, esclarecer continuamente; melhorar a imagem que cada um tem do mundo; verificar como moldar atos e 
decisões; rever nossos modelos mentais e ajustá-los à realidade.

Objetivo comum ou visão compartilhada: estimular o engajamento do grupo em relação ao futuro; elaborar princípios e diretrizes que permitirão alcançar esse futuro.

Aprendizado em grupo: desenvolver o pensamento e a comunicação coletiva a fim de superar a soma dos talentos individuais.

Pensamento sistêmico: analisar e compreender a organização como um sistema integrado. Criar uma forma de analisar e uma linguagem para descrever e compreender as forças e inter-relações que modelam o comportamento dos sistemas.

Para desenvolver essa seção, utiliza-se conhecimentos interdisciplinares de outras áreas para mostrar intencionalmente que o EB, quaisquer outras áreas do conhecimento, empresas e organizações utilizam do mesmo fator interativo, de ensino, de estratégias e desenvolvimento. Conhecimento de diversos especialistas em suas respectivas áreas e disciplinas do conhecimento em geral, como: especialistas em tecnologia; em gestão da informação e do conhecimento; especialista em informação, no uso social da informação e no uso da informação e tecnologia. No EB essa mesma estratégia é utilizada para a construção da doutrina, da área do conhecimento de ciências militares e da produção acadêmica das diversas Escolas militares do Brasil, dentre outros processos. Por isso, na próxima seção apresenta-se como ter acesso a esse conhecimento do EB.

\section{CONHECIMENTO MILITAR NA ERA DIGITAL: AMOSTRA DA PRODUÇÃO DO EB}

O intuito deste ensaio, além de acentuar sobre a produção acadêmica dos militares do EB, também notabiliza um pequeno tutorial para ter acesso aos trabalhos acadêmicos, bem como ao repositório do EB, isto é, conforme o título deste ensaio "Conhecimentos Interdisciplinares do Exército Brasileiro: um mapa para a sociedade civil', procura-se exibir este mapa - passo a passo - para a sociedade civil sobre o acesso, ao conhecimento do EB - teses, dissertação e trabalhos de conclusão de curso dentre outros. 
A plataforma de pesquisas acadêmicas em geral, o EB possui a Biblioteca Digital do Exército (BDEx), criada recentemente na Instituição. É uma plataforma livre ancorada aos sistemas seguros e específicos do EB.

Recentemente a BDEx foi destaque em produção científica nas Américas, sendo reconhecida pela Universidade de Salamanca, na Espanha, formalizada no 56을 Congresso Internacional de Americanistas (ICA), em 2018, com a apresentação do artigo "Biblioteca Digital do Exército: compartilhando informações, conhecimento e integrando a produção científica militar nas Américas"4. A Biblioteca digital tem sido o canal de fomento da produção científica e da discussão dos assuntos de defesa e segurança nacional. Esse projeto inovador foi elaborado pelo Centro de Doutrina do Exército, analisado e selecionado em um universo de mais de dez mil trabalhos para apresentação no ICA. O objetivo da plataforma é proporcionar visibilidade para as produções bibliográficas e científicas (manuais, instruções, regulamentos e artigos, monografias, dissertações e teses) e outras publicações que possam servir de base para pesquisas de interesse dos exércitos do continente americano. $O$ projeto é um banco de dados em formato digital, que abriga temas de doutrina militar e assuntos de interesse do Exército, visando à gestão e à preservação do conhecimento, e à integração com o meio acadêmico (ARAUJO, 2018).

A proposta de modernizar os meios de difusão do Exército com plataformas digitais open source (código aberto), que tiveram custo zero e otimizaram a utilização de recursos humanos, materiais, financeiros e tecnológicos, foi amplamente aceita pela Força, resultando na aprovação da Diretriz da Biblioteca Digital em 27 de março de 2018, o que, além de normatizar importante instrumento no apoio à gestão do conhecimento, também estabelece que os trabalhos de conclusão de cursos de pós-graduação no exterior sejam disponibilizados na Biblioteca (ARAUJO, 2018).

Nesse contexto, a BDEx ultrapassa as barreiras físicas para a difusão do

\footnotetext{
${ }^{4}$ Os autores do artigo "Biblioteca Digital do Exército: compartilhando informações, conhecimento e integrando a produção científica militar nas Américas" são oficiais do Centro de Doutrina do Exército: Cel. Cav Isaías de Oliveira Filho, 1ํㅜㄹ. de Biblioteconomia Ana Izabel Batista da Silva e $2^{\circ}$ Ten. de Arquivologia Priscylla Silva Araujo. Disponível em: http://www.defesanet.com.br/terrestre/noticia/29870/Exercito-e-destaque-em-producaocientifica-nas-Americas/
} 
conhecimento, visto que a tecnologia da informação e comunicação amplia e acelera os fluxos de informação e conhecimento. Em virtude do projeto de portfólio das plataformas digitais de apoio à gestão do conhecimento, iniciado pela BDEx, as produções intelectuais consideradas de interesse da Força são disponibilizadas, atualmente, para públicos dos mais diversos setores da sociedade. Isso alinha a Força à vanguarda da gestão do conhecimento e da informação, como também ao foco principal deste ensaio: mostrar as perspectivas de acesso à informação do EB como o caráter interdisciplinar dos conhecimentos produzidos nesta Força (ARAUJO, 2018).

O conhecimento interdisciplinar do EB está sendo disponibilizado nestas plataformas aqui demonstradas passo a passo, ampliando o processo de compartilhamento de informação e conhecimento desta renomada Força. Este ensaio expõe para a sociedade civil o mapa para este tesouro do conhecimento até o momento desconhecido.

Assim, mostramos abaixo um pequeno tutorial de acesso à plataforma BDEx hospedada no site: http://bdex.eb.mil.br/jspui/, como representada na Figura 1 abaixo. Ela pode ser acessada pela internet, de qualquer lugar do mundo, por civis e militares, possibilitando acesso a informações de toda ordem. Pode ser acessada por qualquer tecnologia e telefone móvel - smartphone - de acesso à internet e com o leitor de PDF. A tipologia do material disponível para o acesso se dará somente neste tipo.

Figura 1 - Página inicial da BDEx

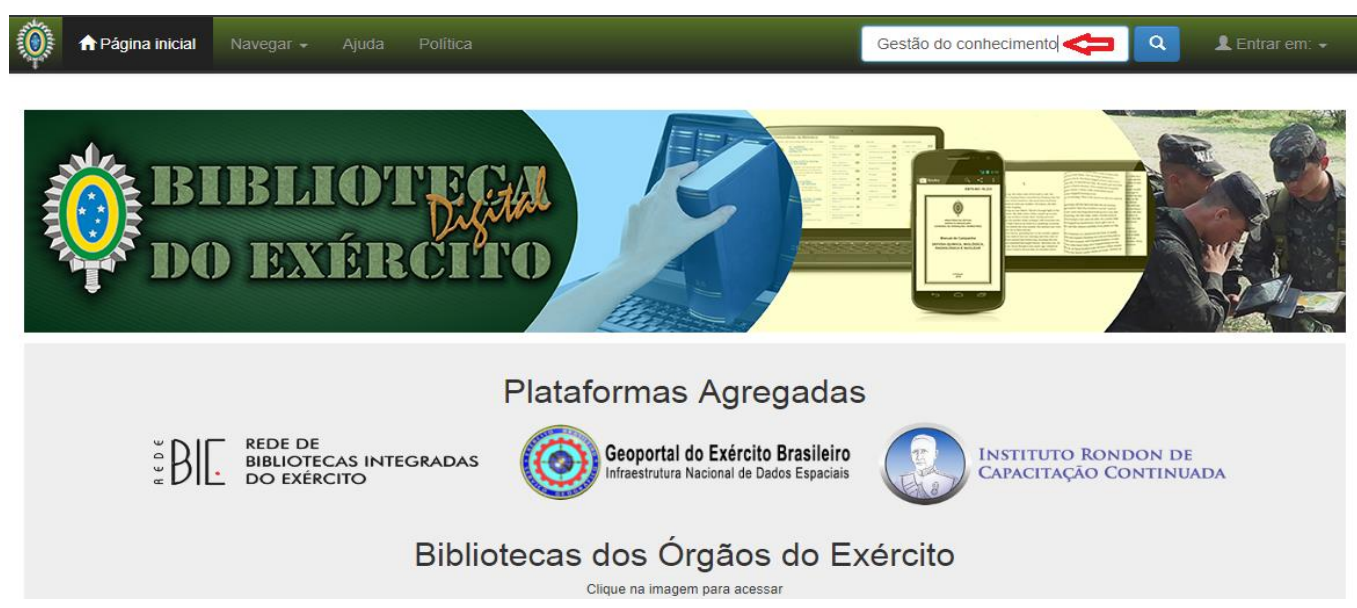

Fonte: Biblioteca Digital do Exército 
Ao acessar a página inicial, conforme a figura 1, com o termo ou não em mente o usuário tem disponível uma gama de filtragens de pesquisa (descer a página). Uma variedade de formas de poder realizar sua pesquisa com sucesso e maestria. Além de poder filtrar por assunto, autores, ano e título, a plataforma utiliza o sistema de busca facetada: em que o usuário, ao encontrar o termo, nome de autores ou do assunto e data de referência logo na página, como demonstrado abaixo, pode somente dar um click em cima da busca e será aberta a pesquisa, seja pelo assunto, nome do autor e tipo de documento. E também, conforme aponta a seta acima digitar o termo da pesquisa ou nome do autor. Assim, sua busca é facilitada, tendo mais precisão e eficácia. Essa busca facetada pelo click na web é conhecida como hipertexto5.

Nesta figura abaixo, utiliza o exemplo do termo "Gestão do Conhecimento". Ao clicar em buscar. Veja o resultado na figura posterior.

\section{Figura 2 - Página de recuperação da informação}

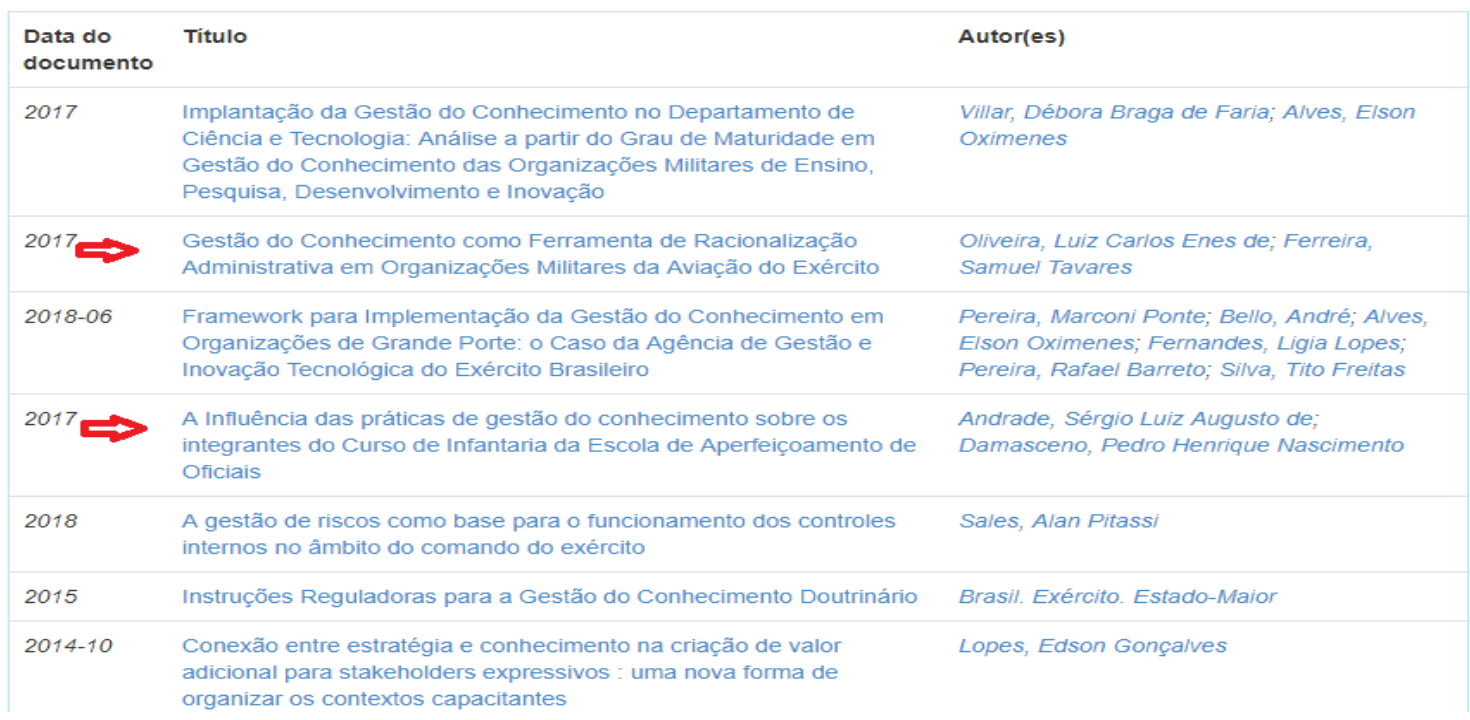

Fonte: Biblioteca Digital do Exército

Ao clicar em cima do registro supracitado abriu-se a página, conforme a

\footnotetext{
5 "Hipertexto é o termo que remete a um texto ao qual se agregam outros conjuntos de informação na forma de blocos de textos, palavras, imagens ou sons, cujo acesso se dá através de referências específicas, no meio digital denominadas hiperligacões. Estas hiperligações ocorrem na forma de termos destacados no corpo de texto principal, ícones gráficos ou imagens, e têm a função de interconectar os diversos conjuntos de informação, oferecendo acesso sob demanda às informações que estendem ou complementam o texto principal". (WIKIPÉDIA, 2018).
} 
figura abaixo.

\section{Figura 3 - Página de download}

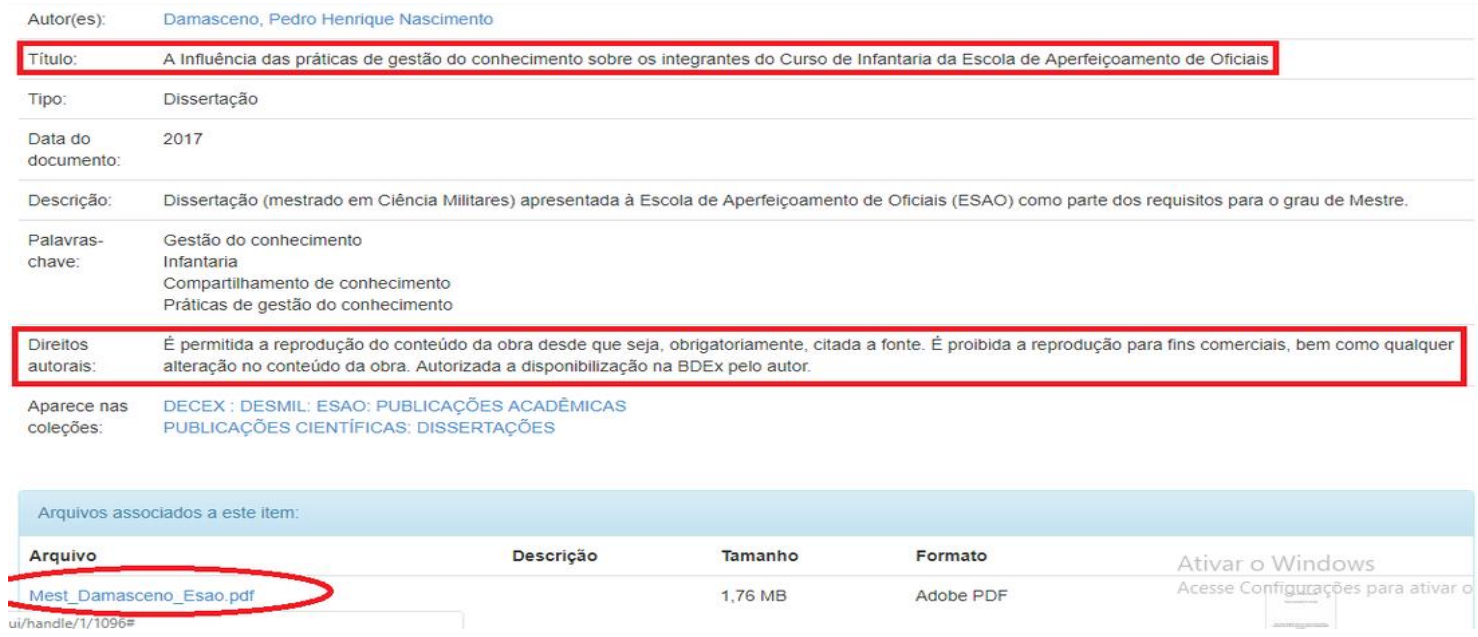

Fonte: Biblioteca Digital do Exército

Além disso, a base permite os filtros para uma busca avançada conforme a figura abaixo.

Figura 4 - Página de filtros para a pesquisa

\begin{tabular}{|c|c|c|c|c|c|}
\hline \multicolumn{2}{|c|}{ Acervo da Biblioteca } & \multicolumn{4}{|c|}{ Filtros } \\
\hline & \multirow{3}{*}{$\begin{array}{l}\text { 01.PUBLICAÇÕES } \\
\text { INSTITUCIONAIS DO } \\
\text { EXERCITO BRASILEIRO }\end{array}$} & Autor & Assunto & \multicolumn{2}{|c|}{ Data de Publicaçăo } \\
\hline & & \multirow{3}{*}{$\begin{array}{l}\text { Brasil. Exército } 1353 \\
\text { Brasil. Exército. Estado- } 200 \\
\text { Maior }\end{array}$} & \multirow{2}{*}{$\begin{array}{l}\text { Engenharia de } \\
\text { transportes }\end{array}$} & \multirow{2}{*}{\multicolumn{2}{|c|}{$\begin{array}{ll}2000-2019 & 1973 \\
1909-1999 & 290 \\
\end{array}$}} \\
\hline & & & & & \\
\hline \multirow{4}{*}{$\begin{array}{l}\text { DE } \\
\text { DE } \\
\text { SA }\end{array}$} & \multirow{4}{*}{$\begin{array}{l}\text { 02.PUBLICAÇÕES } \\
\text { OFICIAIS DE DEFESA } \\
\text { Publicações do Ministério da Defesa, } \\
\text { Marinha do Brasil e Força Aérea }\end{array}$} & & Artilharia & \multirow{2}{*}{\multicolumn{2}{|c|}{ Tipo de Documento }} \\
\hline & & \multirow{2}{*}{$\begin{array}{l}\text { Brasil. Ministério da } \\
\text { Defesa }\end{array}$} & \multirow[t]{2}{*}{ Infantaria } & & \\
\hline & & & & Boletim & 1301 \\
\hline & & \multirow{2}{*}{$\begin{array}{l}\text { Brasil. Exército. Comando } 58 \\
\text { de Oper... }\end{array}$} & Javar & \multicolumn{2}{|c|}{ Dissertação } \\
\hline & \multirow{4}{*}{$\begin{array}{l}\text { 03.DOCUMENTOS } \\
\text { PRODUZIDOS PELO } \\
\text { EXÉRCITO EM } \\
\text { ATIVIDADES DE APOIO } \\
\text { AOS GRANDES EVENTOS }\end{array}$} & & Cavalaria & \multirow{2}{*}{\multicolumn{2}{|c|}{ Monografia }} \\
\hline & & \multirow{2}{*}{$\begin{array}{l}\text { Brasil. Exército. } \\
\text { Departamento Ge... }\end{array}$} & Engenharia & \multirow{2}{*}{\multicolumn{2}{|c|}{ Manual de Campanha 158}} \\
\hline & & & Transporte ferroviário & & \\
\hline & & \multirow{2}{*}{$\begin{array}{l}\text { Brasil. Exército. Comando } 22 \\
\text { Logistico }\end{array}$} & & \multirow[t]{2}{*}{ Norma } & 78 \\
\hline & \multirow{2}{*}{$\begin{array}{l}\text { 04.PUBLICAÇÕES } \\
\text { CIENTIFICAS DE } \\
\text { INTERESSE DO EXÉRCITO }\end{array}$} & & Transporte de cargas & \multirow{2}{*}{\multicolumn{2}{|c|}{ próximo > }} \\
\hline & & $\begin{array}{l}\text { Brasil. Exército. Diretoria } 21 \\
\text { de Fi... }\end{array}$ & Aviação do Exército & & \\
\hline & & \multirow{2}{*}{$\begin{array}{l}\text { Brasil. Exército. } \\
\text { Departamento de... }\end{array}$} & $\begin{array}{l}\text { Produto controlado pelo } 26 \\
\text { Exército ... }\end{array}$ & & $\begin{array}{l}\text { Armas e Assunto } \\
\text { em geral }\end{array}$ \\
\hline & & & \multirow{2}{*}{ próximo > } & \multirow{2}{*}{\multicolumn{2}{|c|}{$\begin{array}{l}\text { Ativar o Windows } \\
\text { Acesse Configuraçōes para ativa }\end{array}$}} \\
\hline & & Brasil. Exército. & & & \\
\hline
\end{tabular}

Fonte: Biblioteca Digital do Exército

O resultado, conforme mostra as duas figuras acima é conveniente para o usuário. Remete ao título do que foi clicado. O usuário possui o acesso na íntegra em PDF e avançadas formas de pesquisa.

O EB possui plataforma de busca e acesso aos seus mais valiosos 
documentos produzidos pelos seus militares, sejam da graduação, pósgraduação, mestrado e doutorado, dentre outros, como artigos, manuais, e até mesmo o catálogo dos livros de todas as bibliotecas do Exército no Brasil. O EB está com o olhar sobre o digital e as tecnologias, a Força dialoga com a sociedade e ao mesmo tempo mostra o que vem sendo produzido por ela.

O EB tem sua produção voltada para a Força. Diferente da sociedade, instituições, e até mesmo as Universidades, que visam o público em geral. No mais, o EB também tem sua gama de produções de caráter multidisciplinar. Em sua produção, há a presença de assuntos interdisciplinares de variados temas relacionados à administração, logística, gestão da informação e do conhecimento, agregando disciplinas de outras áreas do conhecimento para melhorar os serviços, produções intelectuais e o desenvolvimento da Força. Sobre esse tema na próxima seção com a discussão junto com especialistas da área com o foco na dimensão humana e suas contribuições para o público civil.

\section{DAS CIÊNCIAS MILITARES PARA SOCIEDADE CIVIL: PERSPECTIVAS DO EXÉRCITO BRASILEIRO}

Confrontar-se com os problemas é uma atitude esperada de militares corajosos e leais, uma vez que o front convencional não se constitui no único campo de batalha para o oficialato. Diga-se de passagem, as missões diárias e as responsabilidades específicas do comando são cada vez mais intensas e complexas, o que requer oficiais altamente qualificados, cuja atuação possa, efetivamente, contribuir de forma fundamentada e acertada. É justamente por essa razão que a pesquisa se faz necessária, não apenas como princípio formativo para a educação de toda a oficialidade. A pesquisa, entendida como 0 diálogo com a realidade, tem como ponto de partida a reflexão nos contornos das Forças Armadas e, nesse sentido, o compromisso último com sua melhoria e aperfeiçoamento (DURAN, 2010).

Pela amostragem por conveniência selecionando militares e civis especialistas em ciência militares, dentre eles professores, instrutores, de Escolas Militares, oficiais superiores de ampla formação e que possuem conhecimento e convivência com a realidade e com o assunto em questão para 
responder um pequeno questionário. Tais especialistas civis e militares autorizaram sua identificação. A abordagem qualitativa pela amostragem por conveniência, em que o autor seleciona especialistas e membros da população mais acessíveis no momento, e eles são convidados a discutir e responder 0 questionário enviado.

\section{Quadro 1 - Identificação dos especialistas, OM e suas respostas}

\begin{tabular}{|c|c|c|c|}
\hline $\begin{array}{c}\text { Nome do } \\
\text { professor, } \\
\text { instrutor e } \\
\text { oficial superior }\end{array}$ & $\begin{array}{c}\text { Organização } \\
\text { Militar onde } \\
\text { trabalha }\end{array}$ & $\begin{array}{c}\text { Qual a importância e } \\
\text { relevância da produção } \\
\text { intelectual da área das } \\
\text { ciências militares do EB } \\
\text { para a sociedade civil em } \\
\text { geral? }\end{array}$ & Análise do autor \\
\hline $\begin{array}{l}\text { Tenente Coronel } \\
\text { Carlos Eduardo } \\
\text { Luz Gabriel }\end{array}$ & $\begin{array}{l}\text { AMAN - } \\
\text { Academia Militar } \\
\text { das Agulhas } \\
\text { Negras }\end{array}$ & $\begin{array}{l}\text { "De suma importância, } \\
\text { tendo em vista que não } \\
\text { enxergo essa cisão entre } \\
\text { sociedade civil e os } \\
\text { militares, observando a } \\
\text { (Política Nacional de } \\
\text { Defesa) PND, e entendendo } \\
\text { que o verdadeiro assunto } \\
\text { para a sociedade é a } \\
\text { DEFESA em todos os seus } \\
\text { aspectos e abrangências, } \\
\text { ciências militares figuram } \\
\text { com a mesma importância } \\
\text { que qualquer outra ciência } \\
\text { para o desenvolvimento } \\
\text { nacional". }\end{array}$ & $\begin{array}{l}\text { Apesar do } \\
\text { questionado não } \\
\text { relacionar as } \\
\text { ciências militares } \\
\text { diretamente com a } \\
\text { sociedade civil, } \\
\text { acredita que é } \\
\text { importante para a } \\
\text { sociedade todas as } \\
\text { ciências. E que o } \\
\text { foco da ciência } \\
\text { militar é a "defesa" } \\
\text { do Brasil. }\end{array}$ \\
\hline $\begin{array}{l}\text { Major Roberto } \\
\text { Campos Leoni }\end{array}$ & $\begin{array}{l}\text { AMAN - } \\
\text { Academia Militar } \\
\text { das Agulhas } \\
\text { Negras }\end{array}$ & $\begin{array}{l}\text { "Toda a produção } \\
\text { intelectual é importante em } \\
\text { qualquer área do } \\
\text { conhecimento. Na área de } \\
\text { ciências militares não seria } \\
\text { diferente. Particularmente, } \\
\text { sem pesquisa, } \\
\text { desenvolvimento, produção } \\
\text { e serviços na área militar, } \\
\text { não existiria indústria de } \\
\text { defesa" }\end{array}$ & $\begin{array}{l}\text { O questionado } \\
\text { considera importante } \\
\text { para todas as áreas } \\
\text { do saber. } \\
\text { Particularmente a } \\
\text { ciência militar é a } \\
\text { âncora da segurança } \\
\text { em nosso país }\end{array}$ \\
\hline $\begin{array}{l}\text { Coronel da } \\
\text { Reserva do } \\
\text { Exército Brasileiro } \\
\text { Eraldo Francisco } \\
\text { dos Santos Filho }\end{array}$ & $\begin{array}{l}\text { EsAO - Escola de } \\
\text { Aperfeiçoamento } \\
\text { de Oficiais - } \\
\text { Exército } \\
\text { Brasileiro }\end{array}$ & $\begin{array}{l}\text { "Essa pergunta tem amplo } \\
\text { espectro. De maneira muito } \\
\text { simples poderíamos dizer } \\
\text { que há diversos campos de } \\
\text { pesquisa na área de } \\
\text { ciências militares. As } \\
\text { Escolas do Exército que } \\
\text { possuem cursos de } \\
\text { graduação e pós- } \\
\text { graduação, tanto no nível } \\
\text { lato quanto stricto sensu, } \\
\text { têm suas linhas de pesquisa }\end{array}$ & $\begin{array}{l}\text { O inquerido relata } \\
\text { que existe uma } \\
\text { amplitude de } \\
\text { conhecimentos } \\
\text { aplicados e } \\
\text { produzidos no EB em } \\
\text { suas respectivas } \\
\text { Escolas Militares e } \\
\text { linhas de pesquisas. } \\
\text { Tendo com fator } \\
\text { principal na força } \\
\text { terrestre, isto é, na }\end{array}$ \\
\hline
\end{tabular}




\begin{tabular}{|c|c|c|c|}
\hline & & $\begin{array}{l}\text { nas seguintes áreas: } \\
\text { Cultura e Educação, } \\
\text { Doutrina Militar Terrestre, } \\
\text { Administração Militar, } \\
\text { Assuntos da Paz e da } \\
\text { Guerra, História, Saúde, } \\
\text { Ciência e Tecnologia. } \\
\text { Muitas pesquisas estão } \\
\text { focadas em assuntos de } \\
\text { interesse da Força } \\
\text { Terrestre, no entanto, há } \\
\text { pesquisas que podem ser } \\
\text { aplicadas em proveito de } \\
\text { empresas e } \\
\text { consequentemente do } \\
\text { segmento civil da } \\
\text { Sociedade. Cabe uma } \\
\text { ressalva que a sociedade } \\
\text { tem vários segmentos, o } \\
\text { civil e o militar. Não } \\
\text { consideramos em nossos } \\
\text { estudos a sociedade militar, } \\
\text { e sim o segmento militar da } \\
\text { sociedade. Há pesquisa na } \\
\text { área da História que pode } \\
\text { ser útil aos profissionais } \\
\text { deste campo, na área da } \\
\text { ciência e da tecnologia, o } \\
\text { IME tem diversos trabalhos } \\
\text { que são úteis às empresas } \\
\text { e assim podemos constatar } \\
\text { os inúmeros trabalhos de } \\
\text { pesquisas militares. A } \\
\text { maioria desses trabalhos } \\
\text { está focada na doutrina } \\
\text { militar terrestre. Enumerá- } \\
\text { los é muito difícil devido à } \\
\text { ampla quantidade de } \\
\text { assuntos e abrangência } \\
\text { desses trabalhos". }\end{array}$ & $\begin{array}{l}\text { segurança de nosso } \\
\text { país. E que também, } \\
\text { "há pesquisas que } \\
\text { podem ser aplicadas } \\
\text { em proveito de } \\
\text { empresas e } \\
\text { consequentemente } \\
\text { do segmento civil da } \\
\text { Sociedade". Ele } \\
\text { acredita que a } \\
\text { produção do EB é } \\
\text { muito importante } \\
\text { para outras áreas do } \\
\text { conhecimento no } \\
\text { Brasil, relacionando } \\
\text { o que o inquerido } \\
\text { fala de "segmento } \\
\text { militar da sociedade" } \\
\text { onde as forças } \\
\text { armadas e seus } \\
\text { conhecimentos } \\
\text { acompanha, faz } \\
\text { segurança e traz a } \\
\text { paz para nossa } \\
\text { sociedade. }\end{array}$ \\
\hline $\begin{array}{l}\text { Leonardo } \\
\text { Ferreira Barbosa } \\
\text { da Silva }\end{array}$ & $\begin{array}{l}\text { IME - Instituto } \\
\text { Militar de } \\
\text { Engenharia }\end{array}$ & $\begin{array}{l}\text { "Fomentar o conhecimento } \\
\text { nessa área multidisciplinar, } \\
\text { aumentar a visibilidade, } \\
\text { trazer credibilidade para as } \\
\text { ciências militares, fomentar } \\
\text { a pesquisa científica, dentre } \\
\text { outros". }\end{array}$ & $\begin{array}{l}\text { O inquerido acredita } \\
\text { no conhecimento } \\
\text { multidisciplinar para } \\
\text { aumentar a gama de } \\
\text { visibilidade, no EB, } \\
\text { do que está sendo } \\
\text { produzido, dessa } \\
\text { forma ampliando o } \\
\text { conhecimento militar }\end{array}$ \\
\hline $\begin{array}{l}\text { Coronel da } \\
\text { Reserva do } \\
\text { Exército Brasileiro } \\
\text { João Luís Priático } \\
\text { Sapucaia }\end{array}$ & & $\begin{array}{l}\text { "Muito importante pois } \\
\text { reflete nos campos da } \\
\text { segurança para toda } \\
\text { população". }\end{array}$ & $\begin{array}{l}\text { Uma vez que o } \\
\text { campo de atuação, } \\
\text { pesquisas, práticas } \\
\text { militares e de outras } \\
\text { forças são } \\
\text { extremamente } \\
\text { importantes para a } \\
\text { segurança de um } \\
\text { país. }\end{array}$ \\
\hline
\end{tabular}




\begin{tabular}{|c|c|c|c|}
\hline Sabrina & $\begin{array}{l}\text { AMAN - } \\
\text { Academia Militar } \\
\text { das Agulhas } \\
\text { Negras }\end{array}$ & $\begin{array}{l}\text { "Importância: comunicação } \\
\text { científica com o meio } \\
\text { acadêmico civil para } \\
\text { mostrar o que está sendo } \\
\text { feito pelo EB. } \\
\text { Relevância: garantir por } \\
\text { meio da pesquisa que os } \\
\text { possíveis erros sejam } \\
\text { minimizados". }\end{array}$ & $\begin{array}{l}\text { A inquerida relata a } \\
\text { importância da } \\
\text { comunicação e } \\
\text { divulgação do que } \\
\text { vem sendo produzido } \\
\text { no EB com a } \\
\text { relevância de que } \\
\text { esse conhecimento } \\
\text { pode ser utilizado } \\
\text { para modificar os } \\
\text { erros, novas } \\
\text { pesquisas e a } \\
\text { minimização desses } \\
\text { erros. }\end{array}$ \\
\hline $\begin{array}{l}\text { Weslei Jardim } \\
\text { Batista }\end{array}$ & $\begin{array}{l}\text { AMAN - } \\
\text { Academia Militar } \\
\text { das Agulhas } \\
\text { Negras }\end{array}$ & 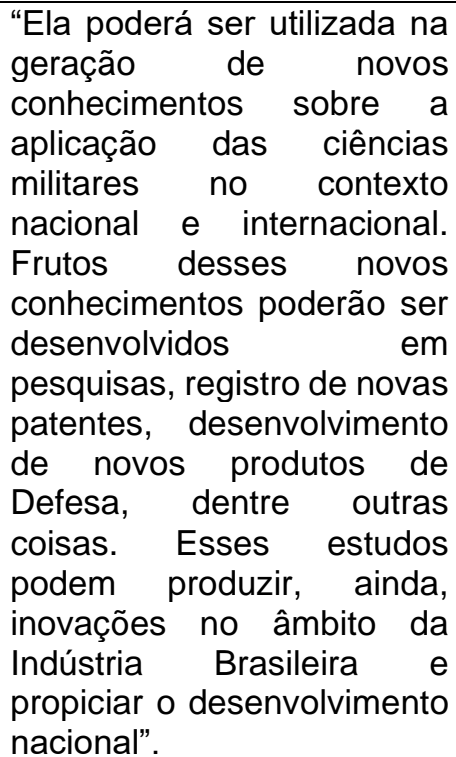 & $\begin{array}{l}\text { O questionado } \\
\text { acredita que os } \\
\text { conhecimentos das } \\
\text { ciências militares são } \\
\text { importantes para o } \\
\text { apoio, seja de âmbito } \\
\text { nacional ou } \\
\text { internacional. Podem } \\
\text { ser desenvolvidos } \\
\text { novos o } \\
\text { conhecimentos, } \\
\text { patentes para } \\
\text { produto de defesa do } \\
\text { Brasil, dentre outras } \\
\text { áreas para o apoio } \\
\text { em novas pesquisas } \\
\text { e desenvolvimento. }\end{array}$ \\
\hline
\end{tabular}

Fonte: Elaborado pelo autor

As ciências militares possuem sua relevância e importância para o país. Como também, revelam-se para a sociedade acadêmica. Ela pode ser útil quando disseminado, conhecido e aproveitado de alguma forma na sociedade. Os especialistas em ciência militares, professores, instrutores deste conhecimento e militares acreditam que essa ciência é importante para a sociedade civil e que pode ser divulgada e ampliada para os civis. Apesar do fato de que essa ciência é e foi criada para o objetivo da defesa nacional do país, bem como sua produção intelectual; as questões práticas, em sua maioria, são voltadas para a defesa do país e da doutrina militar do exército, o que é fato incontestável. Destarte, a produção intelectual do EB vem sendo produzida extensivamente nas Escolas Militares. Os profissionais militares têm como parâmetros esses deveres para sua formação militar e crescimento. A produção 
intelectual do EB convive com a multidisciplinaridade de outras áreas para produzir novos conhecimentos para a sociedade militar e civil.

Os exemplos mostrados de plataforma, com as figuras e formas de acesso, não mostram a totalidade dos conhecimentos produzidos, da relevância dos temas ali inseridos e que podem ser pesquisados, de fácil acesso, de assuntos pertinentes e que poderiam ser aproveitados em diversas instituições acadêmicas, empresariais e outros no Brasil. Esse é o convite ao leitor, de acessar as páginas das plataformas digitais do EB, e que vejam por si mesmos a produção intelectual disponibilizada. A cada ano vão sendo inseridos novos trabalhos, artigos, teses e dissertações sobre diversos temas que podem ser proveitosos de alguma forma, além do mais, os leitores civis, que além de conhecerem a produção intelectual diversificada do EB, irão ter o prazer de conhecer e saber o que os militares fazem para além de serem aguerridos em suas respectivas especialidades.

Por fim, sobre as atividades dos militares que muitos pensam somente de combate, estão enganados. Militares, a cada dia, estudam, produzem e pesquisam sobre diversos assuntos multidisciplinar e conhecimento em geral. Dessa forma, o EB deve ampliar a relação civil e militar. Sobre a relevância do EB, das Forças Armadas e principalmente da educação e a pesquisa (produção intelectual) destes agentes, trecho em que a autora reflete:

Propomos, assim, um trocadilho que sintetiza a ideia de complementaridade na formação profissional militar: nem tarimbeiros, nem bacharéis: "tarimbéis"! Teoria e prática, habilidade operacional e performance intelectual devem ser consideradas como faces indissociáveis da Educação Superior Militar. Eis o desafio pedagógico relacionado à pesquisa como princípio científico e educativo (DURAN, 2016, p. 85, grifo nosso).

\section{CONSIDERAÇÕES FINAIS}

O EB tem suas regras, formas e meios de doutrinar, educar o militar para a vida nas Forças Armadas e na sociedade. As regras e a formação militar são necessárias para o desenvolvimento e aperfeiçoamento do profissional militar. No entanto, se distanciar do mundo civil, conforme aponta a citação acima, é um erro do EB e dos militares em geral. Os militares da Força são o escudo e a lança 
do país. A despeito disso, a Força também deve abraçar e interagir com a sociedade civil e não se isolarem devido ao programa intensivo de sua formação. Essa interação dar-se-á tanto da forma de proteção, união, bem como de trocas de informação, conhecimento para as melhorias e a confecção de novas estratégias para do país, em todos os quesitos e não somente na segurança do país.

Essa troca pode começar pelo conhecimento militar produzido por aguerridos. Ampliando a divulgação do conhecimento da área das ciências militares, das trocas de conhecimento e interação com instituições acadêmicas, profissionais e empresariais. O EB já possui meios para sua divulgação e está aprimorando as formas de acesso para a sociedade em geral. Este ensaio é uma ferramenta para a divulgação dos conhecimentos do EB, como o próprio título indica.

A plataforma digital do EB, como a BDEx, são ferramentas essenciais para o acesso, busca e compartilhamento dos conhecimentos e informações militares. A sociedade civil e cada usuário podem acessar essa plataforma em qualquer horário e lugar do mundo, desde que tenha tecnologia necessária para isso e internet disponível para sua navegação, como também até mesmo pelo celular - smartphone - essas plataformas permitem acesso e leitura da produção intelectual.

Assim, o EB, com sua gama de produção acadêmica, pode almejar maiores alcances e desafios diante de novos cenários tecnológicos, de conhecimentos de variadas áreas que o próprio EB conduz e necessita e produz e compartilha para diversas áreas do conhecimento de empresas no Brasil. Sem falar dos registros históricos e produzidos por essa Força. A depender do material, de sua conservação e local pode ser amplamente acessado e pesquisado por qualquer usuário. O EB está sempre pensando na possibilidade de ampliar o acesso de forma fácil e rápida para a sociedade civil.

Em que o acesso seja garantido em seus mais variados tipos de documentos históricos, revistas e livros raros para a sua digitalização e disponibilização para o público em geral.

Com os dados coletados através do questionário aplicado aos 
especialistas em ciências militares percebe-se sua importância e relevância, bem como o entusiasmo desses inqueridos quanto à possibilidade de um horizonte mais transparente, acessível e conciliação com outras instituições e principalmente com a sociedade civil em geral. O EB está se esforçando para a ampliação e relação com a sociedade civil. Tanto no quesito das relações de pesquisas acadêmicas, da divulgação da produção intelectual, das trocas de conhecimentos interdisciplinares - acadêmica e profissional-, quanto ao simples relacionamento de demonstrar a segurança, união, amizade e empoderamento.

Aqui apresenta-se uma amostra que pode ser considerado uma fonte de informação bibliográfica especializada do EB. Conhecimentos esses que um tempo atrás não eram divulgados e nem acessados pela sociedade civil. Hoje, o EB faz questão de que sua produção seja evidenciada e compartilhada para a sociedade em geral. De forma modesta, o EB vem conquistando os brasileiros com sua nova abordagem no ensino militar e representando o país no exterior com essas plataformas aqui citadas. Essa Força está mais que capacitada para interagir com a sociedade civil, mostrar seus conhecimentos e ampliar sua relação. Ela já não é mais somente aguerrida, faz da segurança de forma impercebível, ela é junto com a Sociedade Civil e o futuro do país a busca da difusão do conhecimento para o país, na humanização do povo e na socialização de tudo que pode ser socializado (o conhecimento explícito e tácito).

\section{REFERÊNCIAS}

ARAUJO, P. S. Exército é destaque em produção científica nas Américas. BIBLIOTECA DIGITAL DO EXÉRCITO, 2018. Disponível em: http://www.defesanet.com.br/terrestre/noticia/29870/Exercito-e-destaque-emproducao-cientifica-nas-Americas/. Acesso em: 05 jan. 2019.

BEAL, A. Gestão estratégica da informação. São Paulo: Atlas, 2011.

BIBLIOTECA DIGITAL DO EXÉRCITO BRASILEIRO. Disponível em: http://bdex.eb.mil.br/jspui/. Acesso em: 04 jan. 2019.

BRASIL. Diretrizes curriculares nacionais para o ensino médio. Parâmetros curriculares nacional - Ensino Médio, Vol. 1. Brasília: Ministério da Educação, Secretaria da Educação Média e Tecnológica, 1999. 
BRASIL. Ministério da Defesa. Política Nacional de Defesa e Estratégia Nacional de Defesa. Brasília, 2012.

CAVALCANTE, L. de F. B; VALENTIM, M. L. P. Informação e Conhecimento no Contexto de Ambientes Organizacionais. In: VALENTIM, M. L. P (org.). Gestão, mediação e uso da informação. São Paulo: Cultura Acadêmica, 2010.

CASTELLS, M. La Era de la información: economía, sociedad y cultura. México: Siglo Veintiuno Editores, 1999.

DAVENPORT, T. H.; PRUSAK, L. Conhecimento empresarial: como as organizações gerenciam o seu capital intelectual. Rio de Janeiro: Campus, 1998.

DURAN, D. Pesquisa na educação superior militar: uma perspectiva pedagógica. Revista Brasileira de Estudos de Defesa, v. 3, n. 2, jul./dez. 2016, p. 73-90. Disponível em:

https://rbed.abedef.org/rbed/article/view/73138pdf. Acesso em: 20 jan. 2019

DURAN, D. Ciências Militares, Militares e Ciência: o desafio da pesquisa no Exército Brasileiro. In: GOMES, J. C.; SHAFFEL, S. L.; DURAN, D. Ciências Militares em foco. Rio de Janeiro: Centro de estudos de pessoal (CEP), 2010.

FAZENDA, I. C. A. Integração e Interdisciplinaridade no Ensino Brasileiro: efetividade ou ideologia. 6 ed. São Paulo: Edições Loyola, 2011.

FAZENDA, I. C. A. (org.). O que é Interdisciplinaridade? São Paulo: Cortez, 2008.

FAZENDA, I. C. A. (org.). Dicionário em construção: Interdisciplinaridade. São Paulo: Cortez, 1993.

GRUNENNVALDT, J. T. A educação militar nos marcos da Primeira República: estudo dos regulamentos do ensino militar (1890-1929). 2005. 296 f. Tese (Doutorado em Educação) - Pontifícia Universidade Católica de São Paulo, São Paulo, 2005. Disponível em:

https://sapientia.pucsp.br/handle/handle/10744. Acesso em: 22 jan. 2019.

JAPIASSU, H. Interdisciplinaridade e patologia do saber. Rio de Janeiro: Imago, 1976.

JAPIASSU, H.; MARCONDES, D. Dicionário básico de filosofia. Rio de Janeiro: Jorge Zahar, 2006.

LÉVY, P. Cibercultura. São Paulo: Ed. 34, 1999

MAGALHÃES, S. M. C. O Processo de Modernização de Ensino (PME) do Exército brasileiro (1995-2001): investigando o ethos e a ação política dos especialistas de ensino. In: ENCONTRO REGIONAL DE HISTÓRIA, 14., Rio de Janeiro, 2010. Anais [...], Rio de Janeiro, 2010. Disponível em: 
http://www.encontro2010.rj.anpuh.org/resources/anais/8/1276564883_ARQUIV O_ArtigodoPos-docparaANPUHR.pdf. Acesso em: 29 abr. 2020.

SENGE, P. M. A quinta disciplina: arte, teoria e prática da organização de aprendizagem. São Paulo: Best Seller, 1998.

SENGE, P. M. A Dança das Mudanças. Rio de Janeiro: Elsevier, 1990.

WIKIPÉDIA. Hipertexto, 2018. Disponível em:

https://pt.wikipedia.org/wiki/Hipertexto. Acesso em: 22 jan. 2019.

\title{
INTERDISCIPLINARY KNOWLEDGE OF THE BRAZILIAN ARMY: A MAP FOR CIVIL SOCIETY
}

\begin{abstract}
Introduction: In this essay we intend to make a theoretical and descriptive discussion about the dimensions of knowledge produced in the Brazilian Army (EB). Objective: the goal is to present to Brazilian society in general, especially civil society, this horizon unexplored by them. To show that the EB is much more than the universe of the barracks and the military organizations, establishing a relation between the knowledge (military sciences) and its diversity of disciplines introduced in the Military Schools of Brazil for the compatriots. Methodology: The essay consists of a theoretical and qualitative approach - by sampling for convenience -, selecting military and civilian experts on the subject of military science, academic teaching and professional practice: invited to answer a questionnaire and discuss about the interdisciplinary knowledge of EB on the prism of civil society. And a sample of the way to EB research. Results: points to promising perspectives of engagement and knowledge sharing for civil society; shows the sources of information and strategic paths of access and search of these valuable knowledge hitherto unknown (by civilians), with this, establishes greater efforts on the part of the EB for the maintenance and conservation of this administration: exchange of information, knowledge and, respectively, means to innovate and create advantages in these two scenarios: civil and military. Conclusions: Finally, it is considered that interdisciplinarity within EB is an essential and emerging demand for the present day, it will give and facilitate greater engagement to interact and socialize in the civil environment, as well as greater visibility in civil society and academic, whether in Brazil or abroad, as a key factor in military organizational development and in the human dimension.
\end{abstract}

Descriptors: Interdisciplinarity. Military knowledge. Intellectual production of the Brazilian Army.

\section{CONOCIMIENTO INTERDISCIPLINARIO DEL EJÉRCITO BRASILEÑO: UN MAPA PARA LA SOCIEDAD CIVIL}

\section{RESUMEN}

Introducción: en este ensayo pretendemos hacer una discusión teórica y descriptiva sobre las dimensiones de los conocimientos producidos en el Ejército Brasileño (EB). 
Objetivo: el objetivo es presentar para la sociedad brasileña en general, especialmente la civil, ese horizonte inexplorado por ellos. En el caso de que el EB sea mucho más que el universo del cuartel y de las organizaciones militares, estableciendo una relación entre el conocimiento (ciencias militares) y su diversidad de disciplinas introducidas en las Escuelas Militares de Brasil para los compatriotas. Metodología: el ensayo se constituye en un enfoque teórico y cualitativo -por el muestreo por conveniencia-, seleccionando a militares y civiles especialistas en el tema ciencia militar, enseñanza académica y práctica profesional: invitados a responder un cuestionario y discutir acerca de los conocimientos interdisciplinarios del EB sobre el prisma de la sociedad civil. Y de una muestra del camino para las investigaciones del EB. Resultados: apunta perspectivas prometedoras del compromiso y compartir los conocimientos para la sociedad civil; (por los civiles), con ello, establece mayores esfuerzos por parte del EB para el mantenimiento y la conservación de esta administración: intercambio de informaciones, conocimientos y, respectivamente, las fuentes de información y caminos estratégicos de acceso y búsqueda de esos preciosos conocimientos hasta ahora desconocidos (por los civiles), con ello, medios para innovar y crear ventajas en estos dos escenarios: civil y militar. Conclusiones: por fin, se considera que la interdisciplinaridad dentro del EB es una demanda esencial y emergente para los días actuales, se dará y facilitará mayor compromiso para interactuar y socializar en el ambiente civil, así como mayor visibilidad en la sociedad civil y académica, sea en Brasil o en el exterior, como factor clave en el desarrollo organizacional militar y en la dimensión humana.

Descriptores: Interdisciplinariedad. Conocimiento militar. Producción intelectual del Ejército Brasileño.

Recebido em: 18/09/2019

Acesso em: 16/11/2019 